\title{
The causal agents of spotting of ornamental gingers (Curcuma alismatifolia Gagnep.) and potential methods of their control
}

\author{
Przyczyny plamistości kurkumy (Curcuma alismatifolia Gagnep.) \\ i możliwości ochrony
}

\section{Anna Jarecka Boncela*}

\begin{abstract}
Summary
The aim of this work was to determine the casual agents of leaf spotting occurring on Curcuma alismatifolia Gagnep and possible methods of thir control. Symptoms of dry brown spots were observed on the leaves, stems and lower side of perianth of $C$. alismatifolia growing in greenhouse conditions. Pathogenicity tests with isolates obtained from diseased plants. Showed that Acremonium sp. was the main cause of disease symptoms on turmeric. The fungicides such as piraklostrobin (Signum 33 WG), fenhexamid (Teldor $500 \mathrm{SC}$ ), tiofanat-methyl (Topsin $500 \mathrm{M}$ ) and grapefruit extract (Biosept Active), greatly inhibited the growth and development of Acremonium sp. An application of piraklostrobin at the concentration of $250 \mu \mathrm{g} / \mathrm{cm}^{3}$ completely inhibited the mycelium growth. Grapefruit extract, fenhexamid and tiofanat-methyl at the concentration of $250 \mu \mathrm{g} / \mathrm{cm}^{3}$ limited the mycelium growth in 70,75 , and $80 \%$ respectively. Preventiv and curative treatments of piraklostrobin, grapefruit extract, fenhexamid and tiofanat-methyl significantly reduced the development Acremonium sp.
\end{abstract}

Key words: Curcuma alismatifolia; control; Acremonium sp.; fungicides

\section{Streszczenie}

Przedstawiono przyczyny plamistości liści Curcuma alismatifolia i możliwości ochrony. Na liściach, szypułach i łodygach C. alismatifolia rosnącej w szklarni obserwowano brązowe suche plamy. Testy chorobotwórczości wykazały, że główną przyczyną choroby kurkumy jest grzyb Acremonium sp. Badane fungicydy: piraklostrobina (Signum 33 WG), wyciąg z grejpfruta (Biosept Active), tiofanatmetylu (Topsin 500 M) i fenheksamid (Teldor 500 SC) silnie hamowały wzrost i rozwój Acremonium sp. Piraklostrobina w stężeniu $250 \mu \mathrm{g} / \mathrm{cm}^{3}$ całkowicie zahamowała wzrost grzybni. Wyciąg z grejpfruta, fenheksamid i tiofanat metylu w stężeniu $250 \mu \mathrm{g} / \mathrm{cm}^{3}$ ograniczał wzrost grzybni odpowiednio w 70, 75 i 80\%. Piraklostrobina, wyciąg z grejpfruta, fenheksamid i tiofanat metylu zastosowane profilaktycznie i interwencyjnie ograniczały rozwój Acremonium sp.

Słowa kluczowe: Curcuma alismatifolia; Acremonium sp.; fungicydy

Instytut Ogrodnictwa

Konstytucji 3 Maja 1/3, 96-100 Skierniewice

*corresponding author: Anna.Jarecka@inhort.pl 


\section{Wstęp / Introduction}

Kurkuma wąskolistna (Curcuma alismatifolia) należąca do rodziny imbirowatych (Zingiberaceae), pochodzi z tropikalnych rejonów południowo-wschodniej Azji. Osiąga około $60 \mathrm{~cm}$ wysokości i ma szerokolancetowate, zaostrzone liście. W ostatnich latach znacznie wzrosło zainteresowanie uprawą tej rośliny na kwiaty cięte oraz jako roślina doniczkowa. Kurkuma jeszcze kilka lat temu była uważana za roślinę praktycznie „nie chorującą”. Aktualnie warunki w szklarni, w jakich rośnie roślina (wysoka wilgotność i temperatura) są idealne do rozwoju patogenów. Częstym objawem obserwowanym przez producentów podczas uprawy kurkumy w szklarni jest pojawianie się na szypułach, liściach oraz przy silnym porażeniu również na kwiatostanach licznych, drobnych, brązowych plam, które silnie obniżają jakość materiału handlowego.

Celem pracy była identyfikacja patogenu powodującego plamistość liści, łodygi i szypuł $C$. alismatifolia oraz ocena skuteczności fungicydów w ograniczaniu rozwoju choroby.

\section{Materiały i metody / Materials and methods}

Izolacja grzybów. Fragmenty (około $5 \mathrm{~mm}$ ) chorych liści, łodyg i szypuł po ich powierzchniowym odkażeniu, wykładano na pożywkę agarowo-ziemniaczano-glukozową (PDA-Merck), po 10 sztuk na szalkę i inkubowano w temperaturze $20-25^{\circ} \mathrm{C}$. Wyrastające kolonie grzybów przeszczepiano na skosy, a po wyrośnięciu segregowano makroskopowo na grupy. Wybrane izolaty z poszczególnych grup po doprowadzeniu do kultur jednozarodnikowych oznaczano do gatunku, posługując się kluczem (Barnett 1960; Ellis 1971; Gams 1971; Arx 1974).

Ocena chorobotwórczości wybranych izolatów grzybów. Do doświadczeń nad patogenicznością wybrano po 10 izolatów pozyskanych gatunków: Alternaria alternata (Fr.) Keissler, Botrytis cinerea Pers., Pestalotiopsis guepinii (Desm.) Stey i Acremonium sp. Krążki grzybni o średnicy $3 \mathrm{~mm}$ wycinano z 7-dniowych kultur rosnących na pożywce PDA i nanoszono na powierzchniowo odkażone liście i łodygi C. alismatifolia. Inokulowane liście i łodygi układano na siatce polietylenowej, w tacach wyłożonych bibułą filtracyjną, nasączoną wodą destylowaną. Kuwety przykrywano folią aluminiową w celu zwiększenia wilgotności. Liście i łodygi inkubowano w temperaturze $25^{\circ} \mathrm{C}$. Do oceny chorobotwórczości każdego z badanych izolatów użyto 40 liści i 40 łodyg. Doświadczenie wykonano w dwóch seriach, w odstępie 30 dni. Po 10 dniach inkubacji wykonano pomiary długości nekrozy. Na podstawie przeprowadzonych obserwacji do dalszych badań wybrano izolat A-2 Acremonium sp. wykazujący najwyższą agresywność spośród badanych czynników chorobotwórczych.

Wzrost grzybni Acremonium sp. (A-2) in vitro. W pierwszym etapie określano wpływ rodzaju pożywki na wzrost grzybni. Badania prowadzono na pożywkach: agarowo-ziemniaczano-glukozowej (PDA), fasolowej zestalonej agarem (LBA), maltozowej (Malt-extract-agar), pożywce mineralnej Czapka zestalonej agarem (CzDA) i agar z peptonem kazeiny, ekstraktu drożdżowego i glukozą (PCA) w temperaturze $20^{\circ} \mathrm{C}$. Pożywka, na której przyrost liniowy grzybni był największy, posłużyła do określenia wpływu temperatury na wzrost grzybni, z ustaleniem temperatury optymalnej dla wzrostu i rozwoju patogenu. $\mathrm{Na}$ środek szalki Petriego o średnicy $90 \mathrm{~mm}$ nanoszono krążek grzybni o średnicy $3 \mathrm{~mm}$ pobrany z 7-dniowej kultury, po czym szalki umieszczano w termostatach, w zakresie temperatury od 7 do $35^{\circ} \mathrm{C}$ na 8 dni. W czasie inkubacji mierzono średnicę grzybni. $\mathrm{Na}$ podstawie pomiarów obliczono powierzchnię grzybni. Doświadczenie prowadzono w dwóch seriach, po 5 szalek dla każdej pożywki.

Oddziaływanie fungicydów w ograniczaniu wzrostu Acremonium sp. in vitro. Do badań użyto Signum $33 \mathrm{WG}$ $(6,7 \%$ piraklostrobiny $+26,7 \%$ boskalidu), Biosept Active (33\% ekstraktu $\mathrm{z}$ nasion i miąższu grejpfruta). Jako preparaty standardowe zastosowano Teldor 500 SC (500 g/l fenheksamidu) i Topsin M 500 SC (500 g/l tiofanatu metylowego).

Doświadczenie A - oddziaływanie fungicydów na wzrost grzybni Acremonium sp. in vitro. Fungicydy dodawano do pożywki PDA w ilości 100, 250 i $500 \mu \mathrm{g} / \mathrm{cm}^{3}$ pożywki. Tak przygotowane szalki z pożywką szczepiono krążkami kultur Acremonium sp. (izolat A-2) o średnicy $5 \mathrm{~mm}$. Po 2, 4, 6 i 8 dniach inkubacji w temperaturze $25^{\circ} \mathrm{C}$ mierzono średnicę kultur $\mathrm{w}$ dwóch prostopadłych kierunkach. Doświadczenie wykonano w 2 seriach po 5 szalek dla każdego stężenia.

Doświadczenie B - oddziaływanie fungicydów stosowanych profilaktycznie $i$ interwencyjnie w ograniczaniu rozwoju Acremonium sp. na liściach $C$. alismatifolia w warunkach laboratoryjnych. Liście pobierano $\mathrm{z}$ roślin zdrowych uprawianych w warunkach szklarniowych. Profilaktycznie wykonano zabieg opryskiwania izolowanych liści zawiesiną preparatów 100,250 i $500 \mu \mathrm{g} / \mathrm{cm}^{3}$, a następnie, po osuszeniu, inokulowano je krążkami 7-dniowej grzybni Acremonium sp. o średnicy $3 \mathrm{~mm}$ rosnącej na pożywce PDA. Interwencyjnie stosowano fungicydy po 2 dniach od inokulacji krążkami grzybni Acremonium sp., tj. na liście $\mathrm{z}$ widocznymi symptomami porażenia. Po inokulacji i zaprawieniu w fungicydach, liście układano na siatce polietylenowej w kuwetach wyłożonych wilgotną bibułą i przykrywano szczelnie folią aluminiową. Po 5 i 10 dniach inkubacji w temperaturze $25^{\circ} \mathrm{C}$ mierzono średnicę nekrozy. Dla każdego fungicydu testowano 40 liści (10 liści w 4 powtórzeniach). Doświadczenie wykonano w dwóch seriach w odstępie 30 dni.

Uzyskane wyniki opracowano statystycznie posługując się metodą analizy wariancji. Do oceny różnic między średnimi użyto testu Duncana, przyjmując poziom istotności $5 \%$.

\section{Wyniki i dyskusja / Results and discussion}

Z chorych liści, łodyg i szypuł $C$. alismatifolia z objawami brązowej plamistości, izolowano głównie $A$. altenata, B. cinerea, Pestalotia sp. i Acremonium sp. Przepro- 
wadzone testy chorobotwórczości wykazały, że główną przyczyną suchych, brunatnych plam, które łączą się ze sobą tworząc duże nekrozy, jest grzyb Acremonium sp. Wszystkie badane izolaty Acremonium sp. wywoływały objawy plamistości na liściach $C$. alismatifolia. Stwierdzono zróżnicowanie w ich agresywności. Długość plam nekrotycznych w następstwie porażenia badanymi izolatami Acremonium sp., mierzona po 14 dniach inkubacji liści w temperaturze $25^{\circ} \mathrm{C}$ wahała się od $8 \mathrm{~cm}$ do $25 \mathrm{~cm}$. Spośród badanych izolatów najbardziej agresywny w rozwoju choroby okazał się izolat A-2, który używano w dalszych badaniach.

Minimalny wzrost grzybni izolatu A-2 Acremonium sp. obserwowano $w$ temperaturze $7-10^{\circ} \mathrm{C}$ oraz w $30^{\circ} \mathrm{C}$ (rys. 1). Grzybnia badanego izolatu rozwijała się najszybciej w zakresie temperatury $20-25^{\circ} \mathrm{C}$. Maksimum wzrostu grzybni stwierdzono w temperaturze $25^{\circ} \mathrm{C}$ zarówno po 2 , 4 i 7 dniach inkubacji (rys. 1). Najlepszymi pożywkami dla wzrostu Acremonium sp. okazały się pożywki PCA i LBA. Nieco słabszy wzrost obserwowano na pożywkach PDA i maltozowej, a najwolniej przebiegał wzrost liniowy grzybni na pożywce Czapka.

W warunkach in vitro preparat Signum 33 WG wykazał silnie fungitoksyczny wpływ na wzrost liniowy grzybni Acremonium sp. Piraklostrobina w stężeniu $100 \mu \mathrm{g} / \mathrm{cm}^{3}$ pożywki hamowała wzrost grzybni patogenu w $95 \%$, a w stężeniu $250 \mu \mathrm{g} / \mathrm{cm}^{3}$ wystąpiło całkowite zahamowanie wzrostu grzybni (rys. 2). Tiofanat metylu, fenheksamid

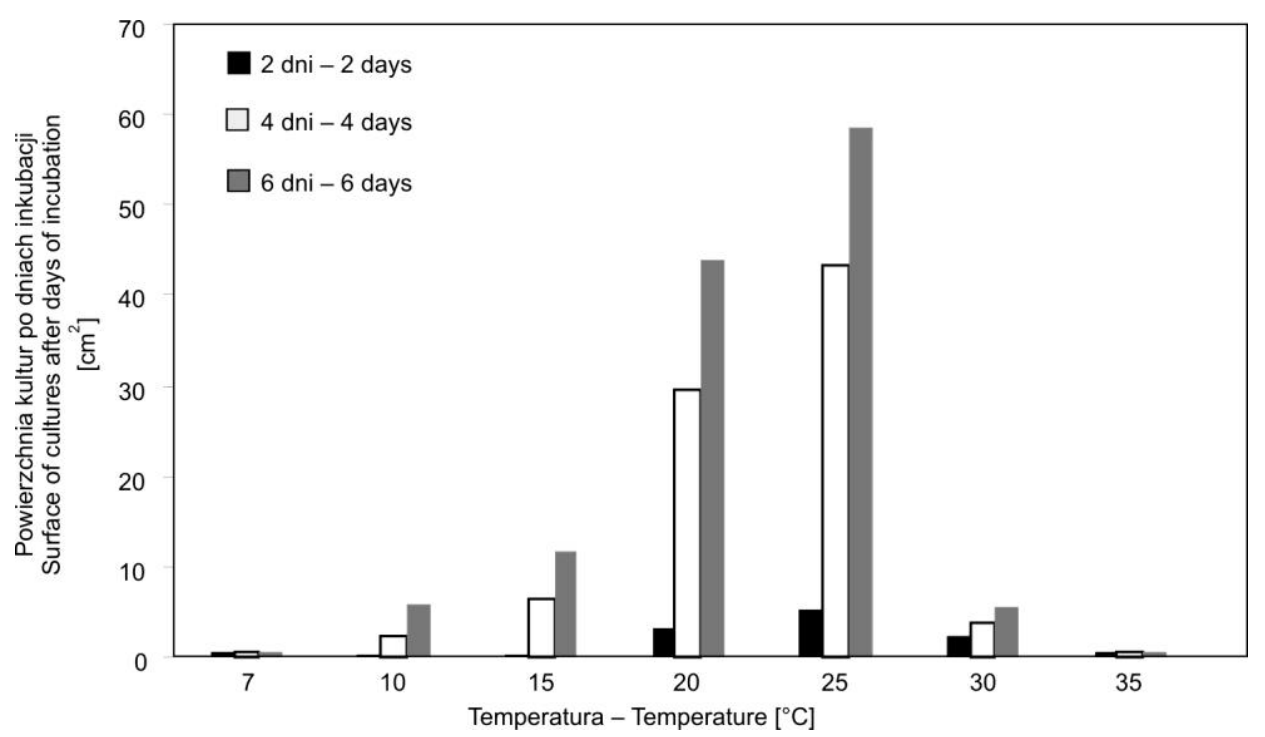

Rys. 1. Wpływ temperatury na wzrost $\left[\mathrm{cm}^{2}\right]$ kultur Acremonium sp. na agarze z peptonem kazeiny, ekstraktem drożdżowym i z glukozą (PCA)

Fig. 1. Influence of temperature on the growth $\left[\mathrm{cm}^{2}\right]$ of Acremonium sp. cultures on casein peptine, yeast agar and glucose medium (PCA)

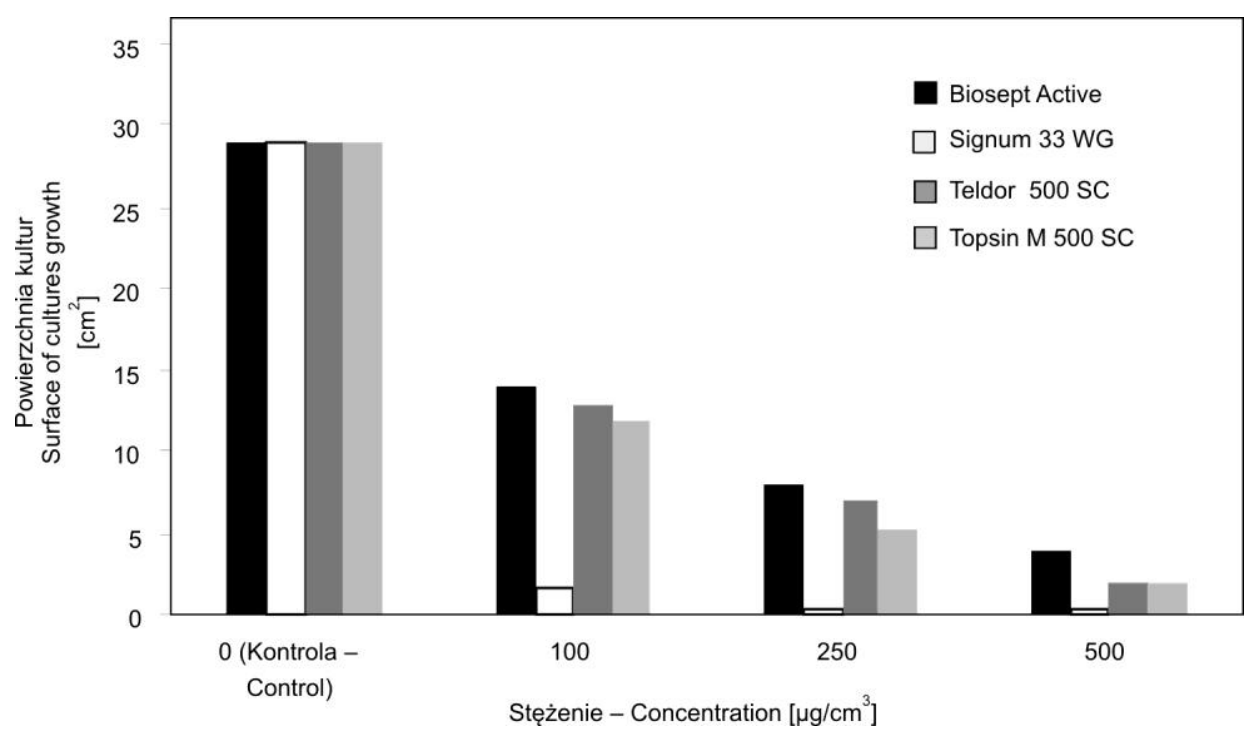

Rys. 2. Wpływ fungicydów na wzrost $\left[\mathrm{cm}^{2}\right]$ kultur in vitro Acremonium sp., po 8 dniach inkubacji

Fig. 2. Influence of fungicides on the in vitro growth $\left[\mathrm{cm}^{2}\right]$ of Acremonium sp., cultures 8 days after incubation 
Tabela 1. Wpływ fungicydów stosowanych profilaktycznie na rozwój Acremonium sp. na liściach Curcuma alismatifolia

Table 1. Influence of fungicides preventively applied on the development of Acremonium sp. on Curcuma alismatifolia leaves

\begin{tabular}{|c|c|c|c|}
\hline \multirow[t]{2}{*}{$\begin{array}{c}\text { Traktowanie } \\
\text { Treatment }\end{array}$} & \multirow{2}{*}{$\begin{array}{c}\text { Stężenie } \\
\text { Concentration } \\
{\left[\mu \mathrm{g} / \mathrm{cm}^{3}\right]}\end{array}$} & \multicolumn{2}{|c|}{$\begin{array}{l}\text { Długość nekrozy po dniach inkubacji } \\
\text { Length of necrotic spot after days of incubation } \\
{[\mathrm{mm}]}\end{array}$} \\
\hline & & 7 & 12 \\
\hline Kontrola - Control & - & $11,1 \mathrm{f}$ & $25,2 \mathrm{f}$ \\
\hline Signum $33 \mathrm{WG}$ & 100 & $1,6 \mathrm{a}$ & $2,2 \mathrm{~b}$ \\
\hline Signum 33 WG & 250 & $0,9 \mathrm{a}$ & $1,0 \mathrm{a}$ \\
\hline Signum $33 \mathrm{WG}$ & 500 & $0,9 \mathrm{a}$ & $1,0 \mathrm{a}$ \\
\hline Biosept Active & 100 & $7,0 \mathrm{e}$ & $11,2 \mathrm{e}$ \\
\hline Biosept Active & 250 & $4,3 \mathrm{~d}$ & $9,2 \mathrm{~d}$ \\
\hline Biosept Active & 500 & $2,2 \mathrm{c}$ & $6,9 \mathrm{c}$ \\
\hline Teldor 500 SC & 100 & $6,8 \mathrm{e}$ & $11,0 \mathrm{e}$ \\
\hline Teldor $500 \mathrm{SC}$ & 250 & $4,4 \mathrm{~d}$ & $8,7 \mathrm{~d}$ \\
\hline Teldor $500 \mathrm{SC}$ & 500 & $4,0 \mathrm{c}$ & $6,1 \mathrm{c}$ \\
\hline Topsin M 500 SC & 100 & $6,5 \mathrm{e}$ & $10,8 \mathrm{e}$ \\
\hline Topsin M 500 SC & 250 & $4,2 \mathrm{~d}$ & $8,0 \mathrm{~d}$ \\
\hline Topsin M 500 SC & 500 & $1,8 \mathrm{~b}$ & $5,8 \mathrm{c}$ \\
\hline
\end{tabular}

Średnie w kolumnach oznaczone tą samą literą nie różnią się istotnie przy (5\%); wielokrotny test Duncana

Means in columns followed by the same letter do not differ at $5 \%$ level of significance; Duncan's multiple range test

Tabela 2. Wpływ fungicydów zastosowanych interwencyjnie na rozwój Acremonium sp. na liściach Curcuma alismatifolia Table 2. Influence of fungicides applied curatively on the development of Acremonium sp. on Curcuma alismatifolia leaves

\begin{tabular}{|c|c|c|c|}
\hline $\begin{array}{c}\text { Traktowanie } \\
\text { Treatment }\end{array}$ & $\begin{array}{c}\text { Stężenie } \\
\text { Concentration } \\
{\left[\mu \mathrm{g} / \mathrm{cm}^{3}\right]}\end{array}$ & $\begin{array}{c}\text { Długość nekrozy po } 2 \text { dniach } \\
\text { od inokulacji liści } \\
\text { Length of necrotic spot after } 2 \text { days } \\
\text { inculation leaves } \\
\text { [mm] }\end{array}$ & $\begin{array}{c}\text { Długość nekrozy po } 10 \text { dniach } \\
\text { od opryskiwania liści środkami ochrony } \\
\text { Length of necrotic spot } 10 \text { days } \\
\text { after spraying leves } \\
\text { [mm] }\end{array}$ \\
\hline Kontrola - Control & - & $4,2 \mathrm{a}$ & $28,4 \mathrm{e}$ \\
\hline Signum 33 WG & 100 & $3,9 \mathrm{a}$ & $10,0 \mathrm{~b}$ \\
\hline Signum $33 \mathrm{WG}$ & 250 & $3,9 \mathrm{a}$ & $5,8 \mathrm{a}$ \\
\hline Signum $33 \mathrm{WG}$ & 500 & $4,1 \mathrm{a}$ & $5,1 \mathrm{a}$ \\
\hline Biosept Active & 100 & $4,3 \mathrm{a}$ & $18,1 \mathrm{~d}$ \\
\hline Biosept Active & 250 & $4,2 \mathrm{a}$ & $17,1 \mathrm{~d}$ \\
\hline Biosept Active & 500 & $4,3 \mathrm{a}$ & $16,1 \mathrm{~d}$ \\
\hline Teldor $500 \mathrm{SC}$ & 100 & $4,2 \mathrm{a}$ & $17,2 \mathrm{~d}$ \\
\hline Teldor $500 \mathrm{SC}$ & 250 & $4,0 \mathrm{a}$ & $15,9 \mathrm{~d}$ \\
\hline Teldor 500 SC & 500 & $4,0 \mathrm{a}$ & $14,2 \mathrm{c}$ \\
\hline Topsin M 500 SC & 100 & $4,1 \mathrm{a}$ & $16,0 \mathrm{~d}$ \\
\hline Topsin M 500 SC & 250 & $4,0 \mathrm{a}$ & $14,1 \mathrm{c}$ \\
\hline Topsin M 500 SC & 500 & $3,9 \mathrm{a}$ & $13,1 \mathrm{c}$ \\
\hline
\end{tabular}

Średnie w kolumnach oznaczone tą samą literą nie różnią się istotnie przy (5\%); wielokrotny test Duncana

Means in columns followed by the same letter do not differ at $5 \%$ level of significance; Duncan's multiple range test

i wyciąg z grejpfruta w stężeniu $250 \mu \mathrm{g} / \mathrm{cm}^{3}$ ograniczały wzrost grzybni odpowiednio w 80, 75 i 70\%. Wyższe stosowane stężenia tych środków ochrony nie zahamowały całkowicie wzrostu grzybni patogenu (rys. 2). Fungicyd Signum 33 WG stosowany profilaktycznie silnie ograniczał rozwój Acremonium sp. na liściach C. alismatifolia w porównaniu do liści kontrolnych (tab. 1). Efekt ochronny tiofanatu metylu, fenheksamidu i wyciągu z grejpfruta był nieco słabszy niż piraklostrobiny, jednak te środki ochrony również silnie ograniczały rozwój choroby (tab. 1). Badane fungicydy zastosowane interwencyjnie do opryskiwania liści ograniczały rozwój choroby w około $75 \%$ (tab. 2).

Wcześniejsze badania wykazały wysoką skuteczność fungicydów strobilurynowych w zwalczaniu między innymi rdzy chryzantemy Puccinia horiana (Wojdyła 
2007), rdzy wierzby Melampsora epitea (Wojdyła 2008a), mączniaka prawdziwego róży Sphaerotheca pannosa var. rose (Wojdyła 2008b) oraz czarnej plamistości róż Diplocarpon rosae (Wojdyła 2009). W literaturze istnieje wiele informacji o wysokiej skuteczności grzybobójczej fungicydów typu strobilurin. Grupa związków wykazuje dobre działanie zapobiegawcze i wyniszczające. Poza bezpośrednim hamującym wpływem strobilurin na grzyby, związki te zmieniają równowagę hormonalną $\mathrm{w}$ roślinach (Grossmann i wsp. 1999). W preparacie Biosept Active substancjami biologicznie czynnymi są przede wszystkim endogenne flawonoidy (Saniewska 2002) oraz alifatyczne aldehydy, monoterpeny i notkaton (Caccioni i wsp. 1998). Związki te w badaniach in vitro hamowały wzrost i rozwój wielu bakterii oraz grzybów, takich jak: Penicillium, Colletotrichum i B. cinerea (Esterio i wsp. 1992; Angioni i wsp. 1998; Woedtke i wsp. 1999). Flawonoidy tworzące się $\mathrm{w}$ wielu gatunkach roślin $\mathrm{w}$ następstwie infekcji przez patogeniczne mikroorganizmy odgrywają ważną rolę w reakcji obronnej podczas rozwoju choroby. Związki te hamują kiełkowanie zarodników, wzrost strzępki rostkowej i strzępki grzybni przez uszkodzenie systemów membranowych (Dakora 1995). Wcześniejsze badania wykazały również fungistatyczny wpływ preparatu Citrosept na wzrost liniowy: B. cinerea, B. tulipae, Phoma narcissi,
F. oxysporum f. sp. callistephi, f. sp. narcissi, Phoma poolensis, Sclerotinia sclerotiorum i Rhizoctonia solani (Saniewska 2004; Saniewska i Jarecka 2006). Saniewska i wsp. (2005) wykazali wysoką skuteczność preparatu Biosept 33 SL w ograniczaniu rozwoju rdzy malwy ogrodowej. Badania nad oddziaływaniem środka Biosept 33 SL na różne patogeny prowadzili również m.in.: Orlikowski (2001), Orlikowski i Skrzypczak (2001), Orlikowski i wsp. (2001, 2002), Pięta i wsp. (2004) oraz Kućmierz i wsp. (2013).

\section{Wnioski / Conclusions}

1. Preparat Biosept Active zawierający flawonoidy otrzymane $\mathrm{z}$ grejpfruta, można wykorzystać do ochrony roślin przed plamistościami.

2. Fungicydy: Signum $33 \mathrm{WG}(6,7 \%$ piraklostrobiny + $26,7 \%$ boskalidu), Teldor 500 SC (500 g/l fenheksamidu) i Topsin M 500 SC (500 g/l tiofanatu metylowego) stosowane $\mathrm{w}$ warunkach in vitro, profilaktycznie i interwencyjnie silnie ograniczały wzrost i rozwój Acremonium sp. w porównaniu do kontroli.

\section{Literatura / References}

Angioni A., Cabras P., Hellewin G., Pirsi F., Reniero F., Scirra M. 1998. Synthesis and inhibitory activity of 7-geranoxycoumarin against Penicillium species in citrus fruit. Phytochemistry 47: 1521-1525.

Arx J.A. von 1974. The Genera of Fungi Sporulating in Pure Culture. Cramer. Lehre, Vaduz, 315 pp.

Barnett H.L. 1960. Illustrated Genera of Imperfect Fungi. Burgess Publishing Company, Minn, 212 pp.

Caccioni D.R.L., Guizzardi M., Bindi D.M., Renda A., Ruberto G. 1998. Relationship between volatile component of citrus fruit essential oils and antimicrobial action on Penicillium digitatum and Penicillium italicum. International Journal Food Microbiology 43: 73-79.

Dakora F.D. 1995. Plant flavonoids: biological molecules for useful exploitation. Australian Journal of Plant Physiology 22 : 87-99.

Ellis M.B. 1971. Dematiaceous Hyphomycetes. CAB International, Wallingford, UK: 354-357.

Esterio M.A., Auger J.G., Vazquez E., Reyes M., Scheelje F., Verhoeff K. 1992. Efficacy of grapefruit extract BC 1000 for control of Botrytis cinerea on table grapes in Chile. Procceding 10th International Botrytis Symposium Heraklion. Crete, Greece 10-15 September 1992, 545, 10: 211-214.

Grossmann K., Kwiatkowski J., Gaspar G. 1999. Regulation of phytohormone levels leaf senescence and transpiration by the strobilurin kresoxim-methyl in wheat (Triticum aestivum). Journal of Plant Physiology 154: 805-808.

Kućmierz J., Nawrocki J., Sojka A. 2013. Wpływ kilku preparatów biotechnicznych na ograniczenie wzrostu w warunkach in vitro grzybów izolowanych z chorych owoców borówki wysokiej (Vaccinum corymbiferum L.). [Influence of several biotechnical products on growth limitation of fungi isolated from infested fruits of blueberry (Vaccinum corymbiferum L.) in vitro conditions]. Progress in Plant Protection/Postępy w Ochronie Roślin 53 (2): 347-350.

Orlikowski L., Skrzypczak Cz. 2001. Biopreparat z wyciągu z grejpfruta - postęp w biologicznej ochronie roślin przed chorobami. Annales Universitatis Mariae Curie-Skłodowska, E, IX, Suppl.: 261-268.

Orlikowski L., Skrzypczak Cz., Jaworska-Marosz A. 2001. Influence of grapefruit extract on the growth and development of Botrytis spp. and grey mould development on lily and peony. Bulletin of the Polish Academy of Sciences Biological Sciences 49: $375-379$.

Orlikowski L. 2001. Effect of grapefruit extract on development of Phytophthora cryptogea and control of foot rot of gerbera. Journal of Plant Protection Research 41 (3): 288-294.

Orlikowski L., Skrzypczak Cz., Wojdyła A., Jaworska-Marosz A. 2002. Wyciągi roślinne i mikroorganizmy w ochronie roślin przed chorobami. Zeszyty Naukowe Akademii Rolniczej w Krakowie, 387, Sesja Naukowa, 82: 19-32.

Pięta D., Pastucha A., Patkowska E. 2004. Oddziaływanie biopreparatów na wzrost i rozwój niektórych grzybów chorobotwórczych dla roślin motylkowych. Acta Scientiarum Polonorum Hortorum Cultus 3 (2): 171-177.

Saniewska A. 2002. Aktywność antygrzybowa endogennych flawonoidów grejpfruta (Citrus paradise). Materiały Sympozjum Nauk „Fitopatologia polska w Europie”. Warszawa, 17-19 września 2002, 346, 62 ss.

Saniewska A. 2004. Antifungal activity of grapefruit (Citrus paradisi) endogenic flavonoids. Zeszyty Problemowe Postępów Nauk Rolniczych 496: 609-617.

Saniewska A., Jarecka A., Marasek A. 2005. Biopreparat Biosept 33 SL w ograniczaniu rozwoju rdzy malwy ogrodowej. Zeszyty Problemowe Postępów Nauk Rolniczych 504: 689-696. 
Saniewska A., Jarecka A. 2006. Wpływ endogennych flawonoidów grejpfruta (Citrus paradisi Macf.) na wzrost i rozwój dwóch form specjalnych Fusarium oxysporum Schlecht. [Influence of grapefruit (Citrus paradisi Macf.) endogenic flavonoids on the growth and development of two special forms Fusarium oxysporum Schlecht.]. Progress in Plant Protection/Postępy w Ochronie Roślin 46 (2): $517-520$.

Woedtke T., Scluter B., Pfleger P., Lindequist U., Julich U.D. 1999. Aspects of the antimicrobial efficacy of grapefruit seed extract and its relation to preservative substances contained. Pharmacie 54 (6): 452-456.

Wojdyła A.T. 2007. Wpływ związków strobilurynowych na rozwój Puccinia horiana. [Influence of strobilurin compounds on the development of Puccinia horiana]. Progress in Plant Protection/Postępy w Ochronie Roślin 47 (2): 366-370.

Wojdyła A.T. 2008a. Wpływ związków strobilurynowych na rozwój Melampsora epitea. [Influence of strobilurin compounds on the development of Melampsora epitea]. Progress in Plant Protection/Postępy w Ochronie Roślin 48 (2): 548-551.

Wojdyła A.T. 2008b. Wpływ związków strobilurynowych na występowanie mączniaka prawdziwego róży (Sphaerotheca pannosa var. rosae). Zeszyty Problemowe Postępów Nauk Rolniczych 529: 263-269.

Wojdyła A.T. 2009. Wpływ związków strobilurynowych na rozwój Diplocarpon rosae. [Influence of strobilurin compounds on the development of Diplocarpon rosae]. Progress in Plant Protection/Postępy w Ochronie Roślin 49 (1): 301-304. 